\title{
EVALUATION OF MECHANICAL HARVESTING OF OLIVE TREES IN SOME DESERT RIGONS
}

\author{
M.M. Morad $^{1}$, M.Kh. Afify ${ }^{1}$, A.S. El-Kot ${ }^{2}$, Kh.M. Zaky ${ }^{3}$
}

\section{ABSTRACT}

A comb harvesting machine was locally manufactured from low cost, local material to be suitable for olive harvesting. Performance evaluation of the manufactured machine was carried out in terms of harvesting time and comb rotating velocity comparing with four traditional methods of olive harvesting (vibrating comb, shaking the brunches, beating the brunches and climbing the trees using ladder). Three different olive trees varieties (Toffahey, Agezzey and Picual) were harvested by the above mentioned harvesting methods. The results showed that quality percentages of olive were $95.5,75,85,85$, and $85 \%$ for the manufactured comb harvesting machine, vibrating comb, shaking the brunches, beating the brunches and climbing the trees using ladder respectively. The energy requirements values were 9.267, 14.49, 122.9, 122.9 and 122.9kW.h/ton for the same harvesting methods. While the costs values for the harvesting operation were 95.1, 322.36, 2375, 2375 and 2375LE/ton under the same harvesting methods. The best results were achieved with the use of the manufactured comb harvesting machine at comb rotating velocity of 30 rpm during the third harvesting time.

\section{INTRODUTION}

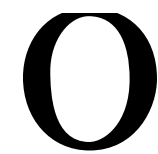

live tree is considered the most important agriculture crop on the new reclaimed desert area in Egypt, and the first source of lighting oil, medicine, as well as feeding. The area of olives is about (120000) fed distributed in El- Faoum, Delta, Sinai (2001-2006, Annon,2008). Because of the local needs many attempts are carried out to increase area and production to cover all aspects of local consumption.

1. Prof. of Agric. Eng. Dep., Fac. Agric. Zagazig Univ.

2. Associate prof. of Agric. Eng., Soil Conservation Dep., D.R.C.

3. Agronomist, South Sinai Research Station. D.R.C. 
Olive harvesting is still operated by traditional method depending on knocking and shaking the branches, using different kinds of comb and manual picking consuming 50-70\% of total costs olive production. Abdel-Maksoud et al., (1992) studied different olive harvesting methods through economical range. They also developed a small scale to determine the required force to pick up olive fruit from branches to produce an olive picker under different conditions of chemical concentrations sprayed before harvesting. They found that the untreated large fruits have the higher values of removal force comparing with small size fruits. But after treatment, the small sized fruits recorded high readings comparing with large ones.

Colorio et al., (1997) determined the working capacity, productivity and principal ergonomic characteristics of compressed air machines used for harvesting olives (cv. Frantoio). Pneumatic equipment was handled manually and consisted of combs (single or double) or hooks used for detaching the olives. They concluded that the best machines were those with vibrating combs; give a high yield, doubling the working capacity of manual collocation with traditional pincers. Vieri (2002) developed an innovative olive harvester with excavator that controls the olive shaker and the gathering umbrella. The module achieved a productivity of 27 olive tree per hour with harvest efficiency of $90.5 \%$. The filed test area is terraced area with olive trees with these features: $22 \mathrm{~m}^{3}$ canopy volume, approximately $15 \mathrm{Kg} /$ plant production, $1.3 \mathrm{~g}$ drupe mean weight, $5 \mathrm{~N}$ detachment resistance. Continues use of the module during the harvest season produced an average productivity of 180 planet/day. MoralesBernardion (2003) described five olive harvesting methods: manual collection of mainly green olives in small receptacles; beating of trunks and branches, manual vibration of trunks; use of mechanical vibrators; and collection of olive from the ground. It is concluded that mechanical harvesting is essential to reduce costs. To obtain good quality oil, olives from the tree and ground should be separated. Methods of harvesting and transport which preserve the epidermis of the fruits will result in high quality oil. Visco et al., (2008) during harvesting olive, found that the application of shaker on the trunk does not give satisfying results. A light shaker which is able to move easily and hook the main branches secures a 
generally high fruit removal of $80 \%$, by shaking an average of 3.2 branches per tree. The Leccino and Frantoio cultivars showed the best results, because of their larger fruits, while with Moraiolo with its smaller fruits and medium fruit detachment force, produced a harvest of only $71 \%$. The average branch volume was between 25 to $40 \mathrm{~m}^{3}$, which can be effective for vibration if applied to right cultivars. Frantoio showed better fruit oil content with respect to Leccino and Moraiolo. Regarding the best time for harvesting, Leccino showed better results during the medium and the late periods of harvesting, when the fruit oil content also increased, while the fruit detachment force remained at about the same level. Ravetti (2008) evaluated Five different harvesters, including a side-by-side shaker (Haslett Harvesting), a grape harvester (new Holland/Braud), a modified coffee harvester (Haslett Harvesting), and two specifically developed machines operating with beating systems (Gregoire $133 \mathrm{~V}$ ) or rotating heads with flexible fingers (Colossus). The parameters that have been evaluated are speed of operation, efficiency of fruit removal, canopy damage trunk damage and cost of operation.. Large over-the-row harvesters like Colossus and side-by- side shakers are competitive alternatives for harvesting full canopy size trees with both advantages and disadvantages.

The above mentioned review shows that olive mechanical harvesting is still a question to be answered. So, the objectives of the present study are to:

1- Study some characteristics of three types of olive trees having a large, medium and small sized fruits.

2- Manufacture, develop and test a local mechanical harvesting machine for olive harvesting.

3- Optimize some operating parameters affecting the performance of the manufactured olive harvesting machine.

4- Compare the performance of the manufactured machine with a vibrating comb and another three manual methods of olive harvesting from the economic point of view. 


\section{MATERILAS AND METHODS}

\section{Materials}

The following equipments were used in this study:

\section{- The manufactured olive harvester}

Introducing a harvesting unit, for olive trees, to meet the farmers' needs and to satisfy the specification of the export markets was found to be necessary. So, a local harvesting unit was designed and locally manufactured.

The unit based on applying tensile (tension) force (comb harvesting machine). The construction feature of the comb-harvesting machine with tension detachment unit was developed mainly consisting of the following components: picking comb, carrying frame, crank and rocker mechanism, chains and differential, , tractor Belarus $90 \mathrm{hp}$ as a power unit. The theory of working of this machine depends on transferring the rotating motion of the crank to reciprocating motion by the harvesting parts, the Belarus tractor generate the rotating motion by p.t.o to the differential which consists of 2 gears with $150 \mathrm{~mm}$ diameter to transfer the motion to the perpendicular direction then the motion is transferred to the comb by two chains and gears that combined with crank and rocker mechanism so that to force the comb to move in a reciprocating motion with a half circle. The comb which takes a shape of half circle with $3 \mathrm{~m}$ diameter, is fabricated from steel plate $50^{*} 10 \mathrm{~mm}$ and fingers from steel with length $200 \mathrm{~mm}$ and diameter $8 \mathrm{~mm}$, the distance between finger started at the base with $32 \mathrm{~mm}$ ending with $25 \mathrm{~mm}$. By the movement of the tractor, the olive fruits entered between the fingers and detached by the tension force which resulted by the motion. All parts of the manufactured machine were carried on a steel frame which is provided with 4 rubber wheels.

The manufactured harvesting machine is shown in figs. 1, 2 .

\section{-Vibrating comb}

The vibrating comb model LISAM with its detachment unit is shown in fig (3). The vibrating comb includes the following components: Electric motor. - 12V-battery. - Fourteen fingers. - Telescopic rod. - 


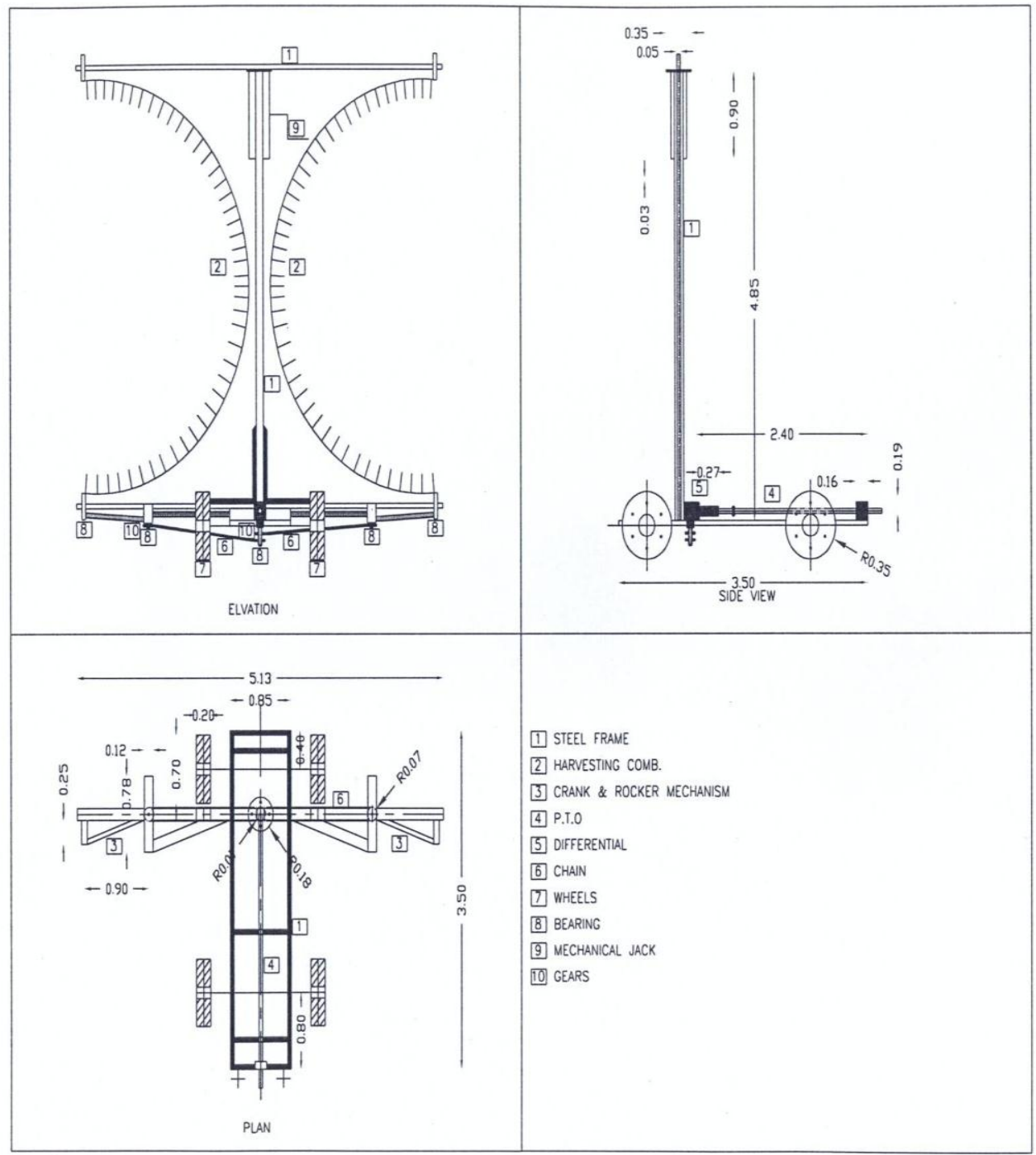

Fig.1: Schematic diagram of the manufactured comb-harvesting machine

- Maximum speed of the vibrating comb is 3000rpm -Varity of olive-trees

Three different cultivars of olive-trees, namely Toffahey, Agezzy and Picual were used in this study. 


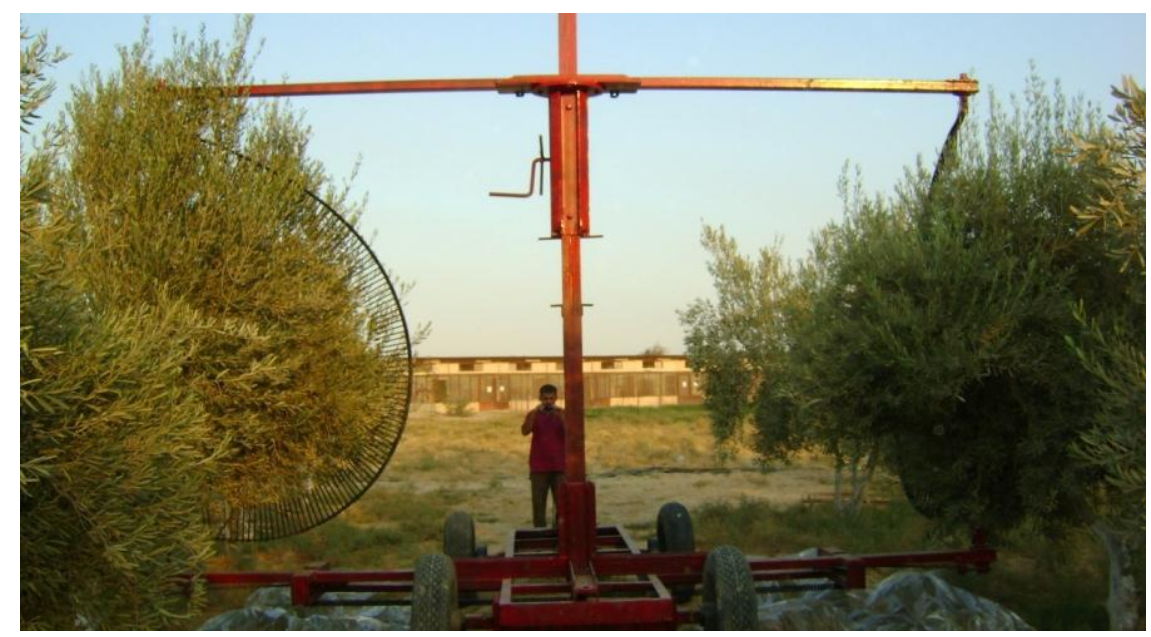

Fig.2: The manufactured harvesting machine during field experiments

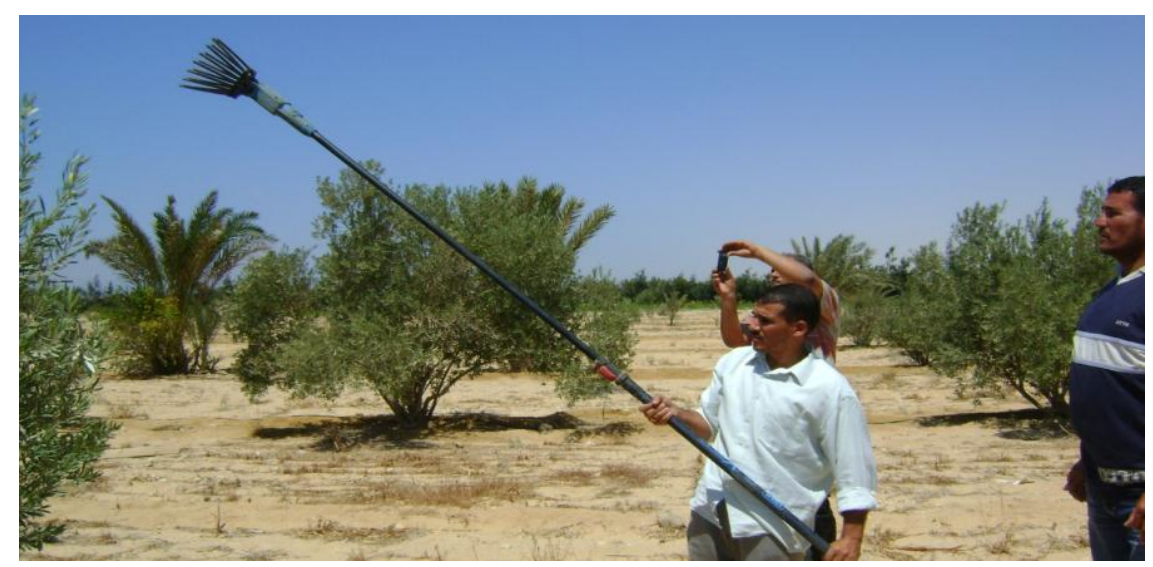

Fig.3: A vibrating comb harvesting model during filed experiments

\section{- Methods}

The physical and mechanical properties of the olive-trees cultivars Toffahey, Agezzy and Picual, were measured during the harvesting seasons of 2008-2009 and 2009-2010 at South Sinai Research Station.

Preliminary tests were conducted at Desert Research Center, Zagazig University workshops and at the same mentioned research farm during the harvesting seasons of 2008-2009 and 2009-2010. However, the field experiments to evaluate the performance of the manufactured comb- 
harvesting machine, and the vibrating comb comparing with the traditional methods of olive harvesting were carried out at private farms and South Sinai Research Station farm during the harvesting seasons of 2008-2009 and 2009-2010.

\section{- Scope of variables}

To realize the purpose from this study, a series of field experiments were carried out under the following conditions:

1- Three types of olive trees (Toffahey, Agezzy, and picual).

2- Five harvesting methods: The manufactured comb harvesting machine (A) and the vibrating comb (B) were used comparing with three traditional methods (shaking branches (C), beating branches (D) and climbing the tree using ladder (E)).

3- Three harvesting times (early first date (I), medium second time (II) and later third time (III)).

4- Three different comb rotating velocities (30, 60 and $90 \mathrm{rpm})$ in respect to the manufactured machine only.

\section{- Measurements}

\section{-Characteristics of olive-trees}

\section{-position of tree parts}

The position of tree parts above the soil surface were measured on the selected olive-trees, the distance between the points, where the brunch out from the trunk starting with the lowest branches defines the disposition of main branches on the trunk. The angle of inclination of each main branch with respect to the trunk axis is also measured

\section{- Spatial position of fruit (fruit distribution) on the tree}

The spatial position of fruits on tree crown was defined by (Buyanov and Voronuk, 1985) as the percentage of the crop ratio along the horizontal layers and the spherical zones on the crown. First layer from the soil surface (height of $0 \mathrm{~m}$ ) to the height of 1 and the second layer from the height of $1 \mathrm{~m}$ to the height to $2 \mathrm{~m}$. while the third layer from the height of $2 \mathrm{~m}$ to the height of $3 \mathrm{~m}$ and the fourth layer from the height of $3 \mathrm{~m}$ to the top of the tree. 
The spherical zones on the tree crown were marked in width of $1 \mathrm{~m}$ each measuring from the periphery to the center of the tree crown. The harvested fruit were collected and weighted to determine the percentage of fruit distribution on each layer and zone .

\section{- Physical and mechanical properties of olive fruit}

Mass, volume, major and minor diameters, of olive fruits; length and diameter of stems and length and diameter of branches were measured for the three olive varieties as a physical properties. Detachment force for the three olive varieties was also measured as a mechanical property.

\section{-Productivity}

Productivity was measured for each harvesting method by recording the time needed for harvesting a certain quality of olive fruits.

\section{The.harvested.olive.mass, ton}

Productivity $($ ton $/ \mathrm{h})=$

$$
\text { Harvesting.time, } h
$$

\section{-Olive quality}

Olive quality was measured for each harvesting method by taking an area of $1 \mathrm{~m}^{3}$ of the tree and counting the leaves and brunches before and after the harvesting operation.

The percentage of leaves drop and broken branches=

$$
\text { (1- } \left.\frac{\text { No.of.leaves.and.brunches.after.harvesting }}{\text { No.of.leaves.and.brunches.before.harvesting }}\right) \%
$$

Olive fruits quality $=\left(\frac{\text { Weight.of.good.fruits }}{\text { Weight.of .sample }}\right) \%$

\section{- Fuel Consumption power and Energy Requirements}

The required power was calculated by using the measured fuel consumption during harvesting operation. The following formula was used to estimate power (Embaby, 1985):

$$
E P=F c \times \rho_{f} \times \frac{1}{3600} \times L c v \times 427 \times \eta_{t h} \times \eta_{m e c} \frac{1}{75} \times \frac{1}{1.36}----(4)
$$

Where:

$$
\begin{aligned}
& \boldsymbol{P}: \text { power, } \mathrm{kW} ; \quad \boldsymbol{F}_{C}=\text { the fuel consumption, } \mathrm{l} / \mathrm{h} \text {; } \\
& \boldsymbol{\rho}_{f}=\text { the density of fuel }(0.85 \mathrm{Kg} / \mathrm{l} \text { for solar fuel }) \text {; } \\
& \text { L.C. } \boldsymbol{V} \text {. }=\text { Lower colorific value of fuel }(10000-11000 \mathrm{Kcal} / \mathrm{Kg}) \text {; }
\end{aligned}
$$


$\boldsymbol{\eta}_{\text {th }}=$ thermal efficiency of engine tractor (20-35\%for diesel engine);

$\boldsymbol{\eta}_{\text {mec }}=$ Mechanical efficiency of engine $(0,80,0.85$ for diesel engine $)$;

427 = Thermo-mechanical equivalent, $\mathrm{Kg} . \mathrm{m} / \mathrm{Kcal}$;

Estimation of energy requirements was carried out using the following equation:-

Energy.rquirements $(k W . h /$ ton $)=\frac{\operatorname{Re} \text { quired.power }(k W)}{\operatorname{Pr} \text { oductivity }(\text { ton } / h)}------(5)$

\section{Cost analysis}

Machinery hourly cost, which include fixed costs (depreciation, interest, housing, insurance, and taxes) and variable costs (repair and maintenance, fuel, oil and labor) are major capital input for most farmers.

Hourly cost $(\mathrm{LE} / \mathrm{h})=$ Fixed cost + variable cost

The harvesting cost was calculated according to the following equation:

Harvesting cost $(\mathrm{LE} / \mathrm{ton})=\frac{\text { Hourly.cos } t \cdot(\text { LE } / h)}{\text { Productivity } \cdot(\text { ton } / h)}$

\section{RESULTS AND DISCUSSION}

The obtained results will be discussed under the following items:

\section{-Tree Characteristics}

The characteristics of olive-tree were measured for the tested olive trees to obtain data to be considered during designing and manufacturing of the manufactured comb-harvester (table).

Table (1) the main characteristics of the olive tree.

\begin{tabular}{|c|c|c|c|c|c|c|c|c|c|c|}
\hline \multicolumn{2}{|c|}{$\begin{array}{c}\text { Tree } \\
\text { height, } \\
\text { m }\end{array}$} & \multicolumn{2}{|c|}{$\begin{array}{c}\text { Tree } \\
\text { crown } \\
\text { volume, } \\
\text { m }^{3}\end{array}$} & \multicolumn{2}{|c|}{$\begin{array}{c}\text { Trunk } \\
\text { height, } \\
\text { m }\end{array}$} & \multicolumn{2}{|c|}{$\begin{array}{c}\text { Trunk } \\
\text { diameter, } \\
\text { m }\end{array}$} & \multicolumn{2}{|c|}{$\begin{array}{c}\text { Main } \\
\text { branches }\end{array}$} & $\begin{array}{c}\text { Angle of main } \\
\text { branches on } \\
\text { vertical, } \\
\text { degrees }\end{array}$ \\
\hline 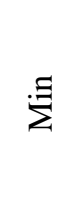 & $\sum_{\Sigma}^{\stackrel{x}{\Sigma}}$ & $\Xi$ & $\sum^{\stackrel{\star}{ \pm}}$ & $\cdot \Xi$ & $\sum^{\stackrel{x}{\Sigma}}$ & $\dot{\Sigma}$ & 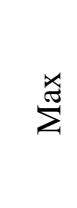 & 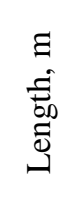 & 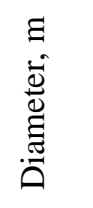 & $120^{\circ}$ \\
\hline 3 & 7 & 14 & 180 & 0.6 & 1 & 0.15 & 0.45 & 2.75 & 0.127 & \\
\hline
\end{tabular}




\section{-Fruit spatial position (fruit distribution) on the tree olive crown}

The results showed that, the highest percentage of the fruit $95 \%$ was found in the periphery of the tree crown (fruit zone 1) followed by $(4.5 \%)$ in the (fruit zone 2) generally, $99.5 \%$ of fruit were found in circumference of the olive-tree within (zone no.1 and 2) for the three olive varieties. The highest percentage of olive fruits were found in layer 2 which represents $64.5 \%$ of the total fruits while, the lowest percentage of $16.5 \%$ was found in the third layer.

\section{-Physical and Mechanical Properties of the harvested olive fruits}

The physical and mechanical properties of the tested olive fruits have been evaluated. The obtained results were used to design the end-effectors of detachment devices (comb-harvester)

\section{-Physical properties of olive fruits}

Olive fruit major and minor diameters were measured. The average major and minor diameters of Toffahey variety were $3.086 \mathrm{~cm}$, and $2.476 \mathrm{~cm}$, While the corresponding values for agezzy variety were $2.76 \mathrm{~cm}$, and $2.194 \mathrm{~cm}$ While, the corresponding values for Picual variety were $2.34 \mathrm{~cm}$ and $1.39 \mathrm{~cm}$, respectively. The olive fruit mass affects the required amount of detachment force of the fruit during harvesting operation.The average mass of olive fruit for Toffahey variety was $9.8 \mathrm{gm}$ while, it was $8.48 \mathrm{gm}$ for Agezzy variety and it was $2.94 \mathrm{gm}$ for Picual variety. The average volume for olive fruits varieties Toffahey, Agezzy and Picual were $10 \mathrm{~cm}^{3}, 9 \mathrm{~cm}^{3}$ and $2.8 \mathrm{~cm}^{3}$ respectively. The dimension of comb finger depend mainly on the actual volume of olive fruit and its mass.

The average stem lengths for olive varieties Toffahey, Agezzy and Picual were $1.38,1.36$ and $0.96 \mathrm{~cm}$ respectively. While the average stem diameter of olive varieties Toffahey, Agezzy and Picual were 0.1446, 0.145 , and $0.10 \mathrm{~cm}$ respectively. The average branch lengths for olive varieties Toffahey, Agezzy and Picual were 86.5, 71, and $77.2 \mathrm{~cm}$ respectively. The average branch diameters for olive varieties Toffahey, Agezzy and Picual were 0.7, 0.64 and $0.36 \mathrm{~cm}$ respectively.

\section{-Mechanical Properties of olive fruits}

\section{-Fruit detachment force}

The F/W ratio (the ratio between detachment force, $\mathrm{F}$ and weight of olive fruit, W) was calculated. The average values of F/W were 87.5, 86.134, 
and 181.136, respectively. For olive varieties Toffahey, Agezzy and Picual The obtained data show that the detachment force depends too much on the fruit mass and varies with the variety of olive and the harvesting date. The relationship between detachment force and the harvesting date was plotted in Fig (4) while the relationship between detachment force and olive mass was plotted in fig (5).

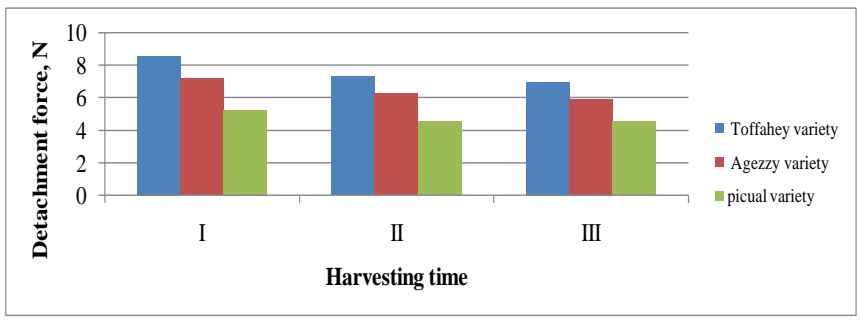

Fig. (4) : The relationship between the harvesting time and its detachment force for the three olive varieties.(I-first time 20/09/2009, II-second time 30/09/2009, III- third time 10/10/2009)

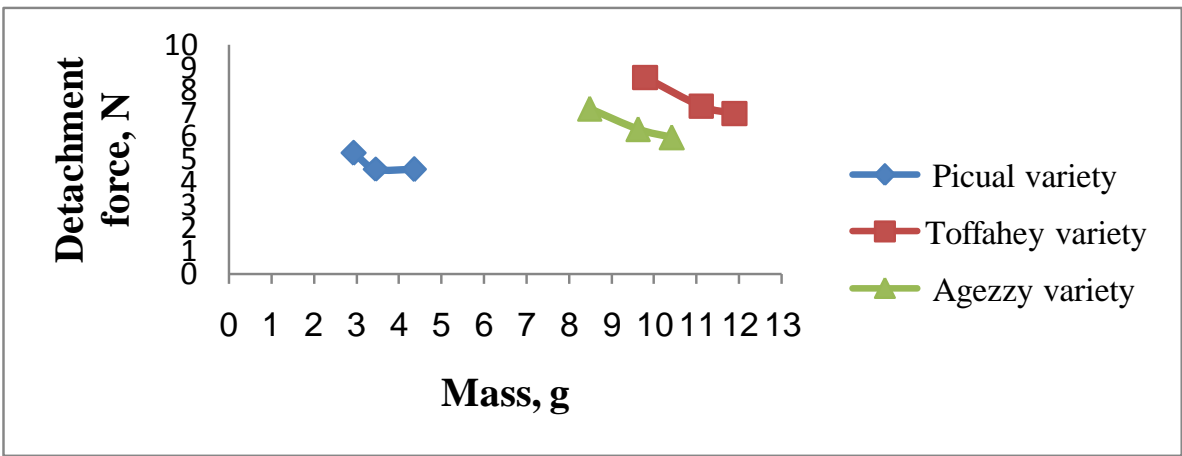

Fig. (5) The relationship between the olive mass and its detachment force for the three olive varieties

It can be seen that the detachment force decreased as the fruit mass increased.

The same results show that detachment force decreased in the third harvesting date comparing with the first and second harvesting dates.

\section{-Effect of harvesting methods on olive quality}


Fruit damage occurred during harvesting operations contributes in decreasing quality of fruits, consequently, decreasing the sailed quantity and manufacturing quality. Any reduction in product quality or saleable yield resulting from fruit damage has a major impact on harvest cost.The effect of harvesting methods on the quality of olive variety Toffahey is shown in fig (6) from this figure. It is noticed that the manufacture combharvester was superior to the other harvesting methods because it gave the highest percentage of fruit grade I of 95\%, (extra fancy).The otained results show that the percentages of fruit grade I (extra fancy) which obtained using the manufactured comb-harvester, vibrating comb, shaking the branches, beating the branches, and climbing the tree using ladder were $95,75,85,85$ and $85 \%$ respectively. These results may be due to the fact that impact force was occurred between fruit and ground surface or harvesting tool or tree branches. On the other hand these harvesting methods gave different percentages of damage branches. These percentages were $1,10,15,15$ and $15 \%$ for the manufactured combharvester, vibrating comb, shaking the branches, beating the branches and climbing the tree using ladder, respectively. Also the drop leaves percentages were 1,20,20,20 and 20under the same harvesting methods. The same trend was obtained for Agezzy variety as shown in fig (6). The percentage of fruits grade I (extra fancy) were 90, 70, 80, 80, and 80\% for the manufactured comb-harvester, vibrating comb, shaking branches, beating the branches and climbing the tree using ladder, respectively. Also the percentages of damaged branches were 2, 15, 20, 20 and 20\%, also the percentages of drop leaves were 1,20, 20, 20 and 20 under the same harvesting methods. The same trend was obtained for Picual variety as shown in fig (6). The percentages of fruits grade I (extra fancy) were $85,65,75,75$, and $75 \%$ for the manufactured comb-harvester, vibrating comb, shaking branches, beating the branches and climbing the tree using ladder, respectively. Also the percentages of damaged branches were 5, $20,22,22$ and $22 \%$, while the percentages of drop leaves were 2, 22, 22, 22and 22 under the same harvesting methods.

\section{-Effect of Harvesting Methods on Energy requirements}

The energy consumed to harvest one ton of olive fruits from olive tree using different harvesting methods was calculated and illustrated in Fig(7). 


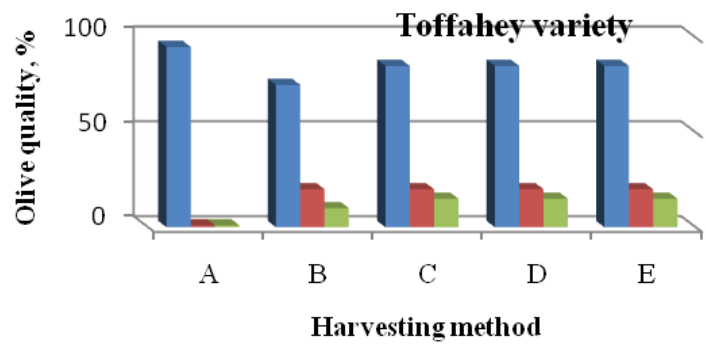

घ extra fancy

- leavs drop

- damaged branches

\section{Agezzy variety}

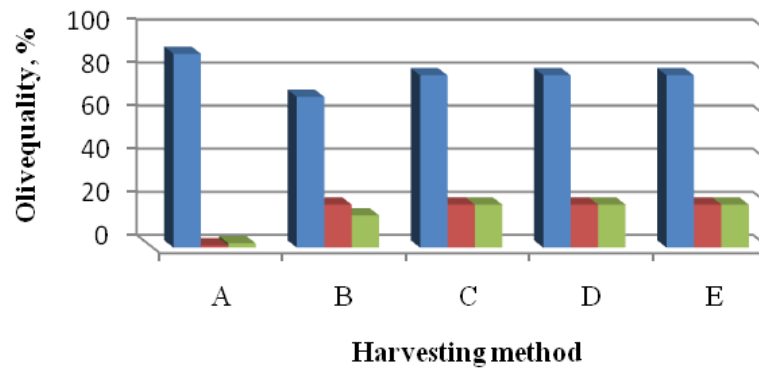

m extra fancy

- leavs drop

- damaged branches

Harvesting method

\section{Picual variey}

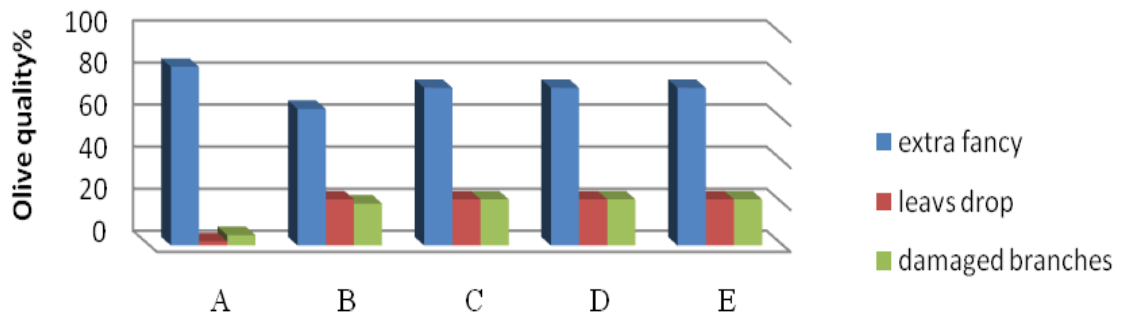

Harvesting method

Fig. (6) : Effect of harvesting methods on olive quality (A-manufactured comb harvesting machine, B-vibrating comb, C-shaking the brunches, D beating the branches, E-climbing the tree using ladder). 
From this Figure it can be observed that using the manufactured combharvester gave the lowest value of energy consumption, $9.267 \mathrm{~kW}$ while the highest value was obtained in case of using traditional methods of harvesting, $122.9 \mathrm{~kW}$.On the other hand, the saving in energy consumption due to the use of manufactured comb-harvester were 56.36, 1226.2, 1226.2 , and $1226.2 \%$ for vibrating comb, shaking branches, beating the branches and climbing the tree using ladder, respectively.

\section{-Cost Evaluation}

The total harvesting cost of the manufactured comb-harvesting machine was $322.36 \mathrm{LE} /$ ton comparing with, $808.566 \mathrm{LE} /$ ton by vibrating comb and $2375 \mathrm{LE} /$ ton by any traditional method, (shaking branches, beating the branches and climbing the tree using ladder) (fig.8). The results indicated that, the expected savings in cost while using the manufactured combharvester reach about $86.43 \%$. On the other hand and according to the price of one ton of olive fruits about $(5000 \mathrm{LE})$, the percentage of harvesting costs by using comb-harvester $6.44 \%$ from the price of olive fruits while it was $16.16,47.5,47.5$ and $47.5 \%$ for vibrating comb, shaking branches, beating the branches and climbing the tree using ladder, respectively.

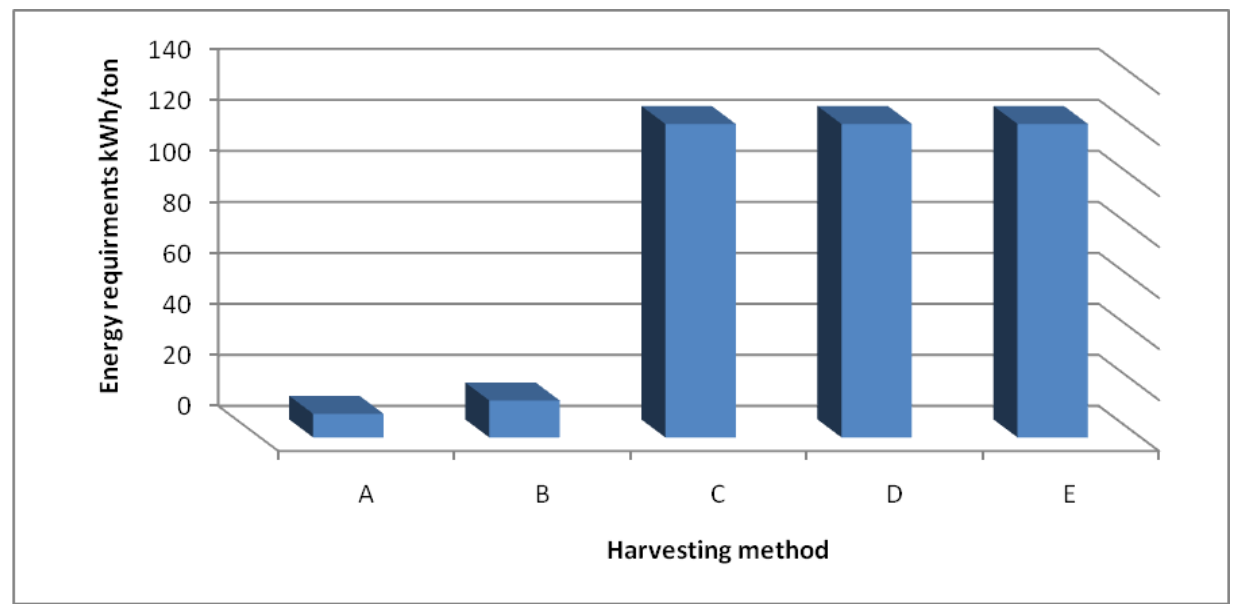

Fig.(7): Effect of harvesting methods on energy consumption, kW.h/ton (A-manufactured comb harvesting machine, B-vibrating comb, C-shaking the brunches, $\mathrm{D}$ beating the branches, E-climbing the tree using ladder) 


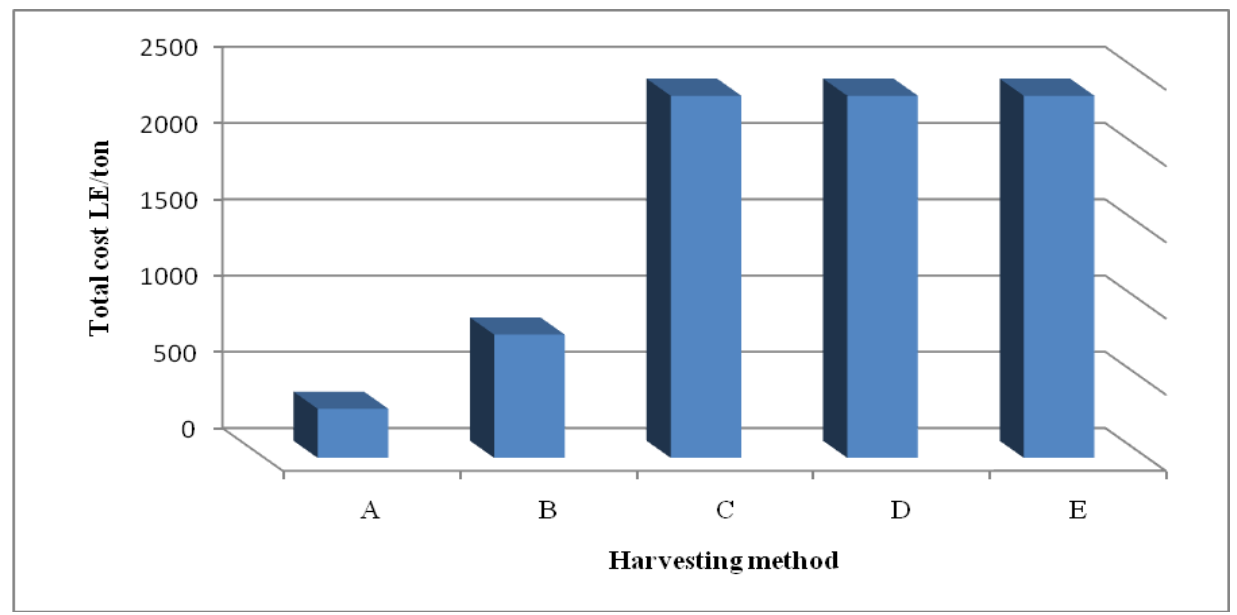

Fig. (8): Effect of harvesting methods on harvesting costs (Amanufactured comb harvesting machine, B-vibrating comb, C-shaking the brunches, D- beating the branches, E-climbing the tree using ladder)

\section{CONCLUSION}

1- Tension detachment method was found to be the best method for picking olive fruits.

2- The manufactured comb harvesting machine is recommended to be used for olive harvesting as it gives the highest product quality.

3- The manufactured comb harvesting machine give the best results at comb rotating velocity of $30 \mathrm{rpm}$.

4- It is recommended to harvest olive during the third time (10/10/2009) to minimize detachment force.

\section{REFERENCES}

\section{Abdel-Maksoud, S. E.; A. I. Hashish, M. S. El-Shal and S. E. Bader,} (1992). A study on selecting the proper system for olive harvesting. Misr J. Ag. Eng., 1992; 9(2): 172-178.

Buyanov, A. I. And B. A. Voronyuk, (1985). Physical and mechanical properties of planting, fertilizers and soils. 111-123, Amerind publishing co. PVT. TD. New Delhi.

Colrio, G.; V. Iannicelli, and L. Ragni, (1997). Compressed air machines to facilitate harvesting olives. Informatore-Agrario. 1997, 53: 44, 53-57. 
Embaby, A. T., (1985). A comparison of the different mechanization systems for cereal crop production. Unpubl. M. Sc. Thesis. Agric. Eng., Cairo Univ.

Morales-Bernardino, j., and C. Garica-Ortiz-Civantos, (2003). The harvest of olive and its influence on the quality of the oil. Agricultura,-Revista-Agropecuaria. 2003; 72 (857): 840-845.

Ravetii, L. M. (2008). Evaluation of new olive mechanical harvesting technologies in Australia. Acta-Horticulture, 2008; (791(Vol1)): 387-392.

Vieri, M. (2002). Olive picking testes with a shaker module and a harvesting umbrella, mounted on a rotating platform excavator. Advances- in-Horticultural-Science. 2002; 16(3/4): 240-245.

Visco, T.; M. Molfese, M. Cipolletti, R. Corradetti and A. Tombesi, (2008). The influence of vibration applied to the trunk and the branches of different size olive trees on the efficiency of mechanical harvesting. Acta-Horticulture, 2008; (791(Vol 1)): 435-438.

Ministry of Agriculture Company and Building Agricultural Research Economics Bulletin, (2008).

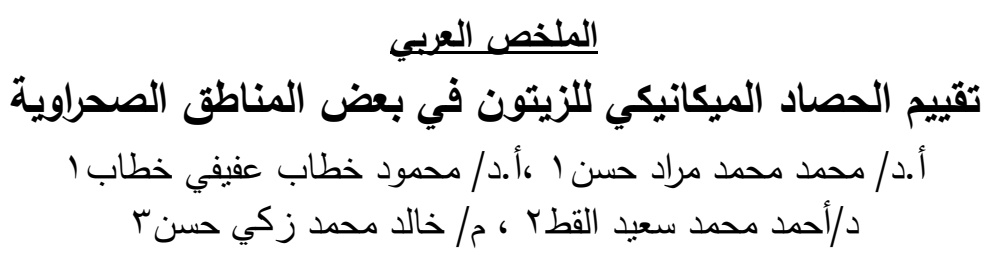




\section{وقد أجريت التجرية باستخدام المعاملات الآتية: \\ أ- حصاد آلي لثلاثة أصناف من الزينون (تفاحي، عجيزي، بيكوال).}

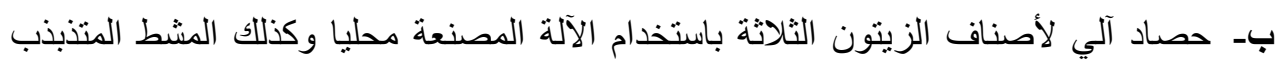

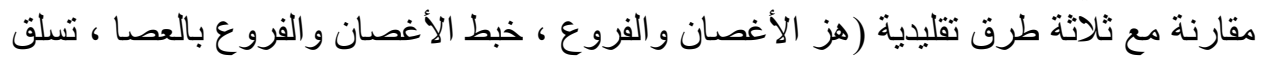

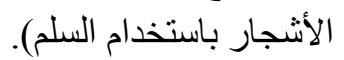

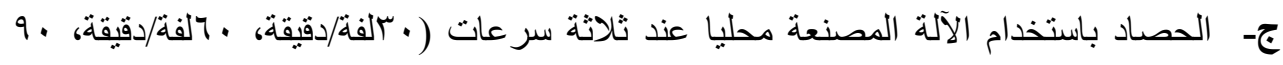
لفة/دقيقة).

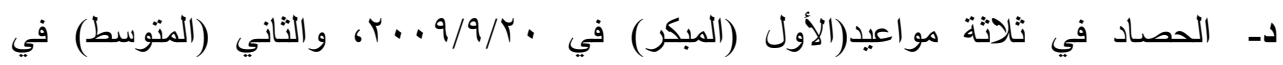

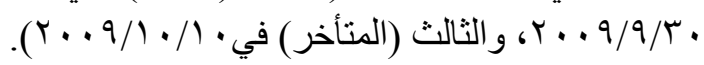

وقد تم تقييم المعاملات من حيث :الإنتاجية والقوة اللازمة للثد وجودة الزيتون المحصود و استهلاك الطاقة و التكاليف. ومن خلال النتائج تم التوصل إلي التوصيات الآتية ا ـ أعطت طريقة الحصاد بالآلة المصنعة محليا أفضل النتائج من حيث جودة الزينون المحصود و انخفاض تكاليف الحصاد. r. أفضل سر عة باستخدام الآلة المصنعة محليا هي • ب لفة في الدقيقة r. يفضل أن يتم الحصاد في الموعد الثالث (المتأخر) حيث تقل القوي اللازمة للثد. 